\title{
EFEITO DA CONDIÇÃO DE ENCHARQUE NO RECOZIMENTO DE UMA LIGA DE ALUMÍNIO 7474-T7351 LAMINADA A TEMPERATURA AMBIENTE *
}

\author{
Saulo Brinco Diniz ${ }^{1}$ \\ Andrey de Moraes Barcelos Casanova ${ }^{2}$ \\ Andersan dos Santos Paula ${ }^{3}$ \\ Luiz Paulo Mendonça Brandão ${ }^{4}$
}

\section{Resumo}

As ligas de alumínio da série 7XXX são largamente utilizadas no setor aeronáutico devido sua alta razão resistência mecânica / densidade. O que proporciona uma alta resistência mecânica para as ligas da série 7XXX é a adição de elementos de ligas e tratamentos térmicos adequados, como por exemplo o T7351. Este trabalho teve como objetivo, estudar a evolução microestrutural de uma liga de alumínio 7475T7351 processada por laminação convencional a temperatura ambiente, e posteriormente submetida a tratamentos térmicos de recozimento para recristalização. De acordo com os resultados apresentados, a amostra que foi submetida ao tratamento térmico de recozimento para recristalização a temperatura de $500^{\circ} \mathrm{C}$ durante 15 minutos recristalizou, enquanto que a amostra que foi tratada a $350^{\circ} \mathrm{C}$ durante 1500 minutos teve coalescimento dos precipitados.

Palavras-chave: Laminação convencional; Recozimento para recristalização; Alumínio 7475-T7351.

\section{SOAKING CONDITION EFFECT ON THE ANNEALING OF A 7475-T7351 ALUMINUM ALLOY ROLLED AT ROOM TEMPERATURE}

\section{Abstract}

The 7XXX aluminum alloys are widely used in the aeronautical industry due to their high mechanical strength / density ratio. Which provides a high mechanical strength for the 7XXX alloys is the addition of alloying elements and heat treatments suitable such the T7351. This work aimed to study the microstructural evolution of a 7475T7351 aluminum alloy processed by rolling at room temperature, and then subjected to annealing heat treatment. According to the results presented, the sample that was subjected to the annealing heat treatment at $500^{\circ} \mathrm{C}$ for 15 minutes recrystallized, while the sample that was heat treated at $350^{\circ} \mathrm{C}$ for 1500 minutes, had a precipitates coalescing.

Keywords: Rolling; Annealing; 7475-T7351 Aluminum.

1 M.Sc., Eng. Metalurgista, Doutorando em Ciência dos Materiais (PGCM/SE-4), IME, Rio de Janeiro - RJ, Brasil; Professor DI - 1, CEFET - Angra dos Reis, Angra dos Reis, RJ, Brasil.

2 M.Sc., Tecnólogo em Processos Metalúrgicos, Doutorando em Ciência dos Materiais (PGCM/SE4), IME, Rio de Janeiro - RJ, Brasil.

3 D.Sc. M.Sc., Eng. Metalurgista, Professora Adjunta (PGCM/SE-4), IME, Rio de Janeiro - RJ, Brasil.

4 D.Sc., M.Sc., Eng. Metalurgista, Professor Associado (PGCM/SE-4), IME, Rio de Janeiro - RJ, Brasil. 


\section{INTRODUÇÃO}

Devido uma série de vantagens que o alumínio e suas ligas possuem, estes são largamente utilizados em várias aplicações, porém o que reduz a sua aplicação é o seu baixo ponto de fusão (660드 para o alumínio puro) e sua baixa resistência mecânica [1 - 4].

As ligas de alumínio se dividem em ligas de fundição e trabalháveis, sendo este último subgrupo as ligas que são submetidas a processos de deformação mecânica durante sua fabricação. Neste subgrupo, as ligas da série $7 \mathrm{XXX}$, são aquelas que tem como elemento de liga principal o $\mathrm{Zn}$, podendo conter também o $\mathrm{Mg}, \mathrm{Cu}, \mathrm{Cr}$ e $\mathrm{Zr}$. Estas ligas apresentam grandes aplicações no setor aeronáutico devido, a elevada razão resistência mecânica / densidade, obtida por estes elementos de ligas e quando submetidas a tratamentos térmicos adequados.

A liga de alumínio 7475 (às vezes denominadas por liga Al-Zn-Mg-Cu) é uma versão modificada da liga de alumínio 7075, e tal modificação se deve a uma redução total do teor de $\mathrm{Fe}$ e Si de 0,90\% para 0,22\%. Dentre os possíveis tratamentos térmicos possíveis de serem realizados nas ligas de Al da série $7 \mathrm{XXX}$, tem-se o tratamento térmico -T7351, no qual tem como finalidade maximizar a resistência à corrosão em detrimento das propriedades mecânicas devido ao superenvelhecimento desta liga.

O tratamento térmico -T7351 para a liga de alumínio 7475 no formato de chapa, consiste em um conjunto de operações que engloba primeiramente um tratamento térmico de solubilização (T7 indica liga solubilizada e estabilizada), no qual é realizado a uma temperatura de encharque de $510^{\circ} \mathrm{C}$ (podendo ter uma variação máxima de $\pm 6^{\circ} \mathrm{C}$ ). Após ser atingido um determinando tempo de encharque, 0 material é retirado rapidamente do forno e resfriado por meio de uma imersão em água a temperatura ambiente. Logo após o tratamento térmico de solubilização é realizado um alívio de tensões por estiramento, para obter uma microestrutura diferenciada para a próxima etapa, no qual é o tratamento térmico de envelhecimento a fim de se ter um superenvelhecimento. Nesta etapa são realizados dois tratamentos térmicos distintos no material, cujo primeiro é conduzido durante 6 a 8 horas de encharque a uma temperatura de $107^{\circ} \mathrm{C}$, e logo em seguida é realizado um outro tratamento térmico de 24 a 30 horas a uma temperatura de $163^{\circ} \mathrm{C}[5,6]$.

Devido à baixa temperatura de fusão do alumínio e suas ligas, ao se realizar um trabalho mecânico a temperatura ambiente este é considerado como trabalho a morno, pois os fenômenos de recuperação podem se fazer presentes (de maneira mais significativa quanto menor for a temperatura de fusão da liga e/ou maior for o incremento de temperatura do material devido a energia térmica gerada com trabalho mecânico).

Após o trabalho mecânico a frio ou morno do alumínio e suas ligas [3, 7], tem-se uma estrutura encruada ou recuperada, e consequentemente um maior limite de resistência. Porém dependendo da aplicação futura do material submetido ao trabalho mecânico, sua utilização não é viável devido à baixa ductilidade resultante, e desta forma é necessário realizar um tratamento térmico posterior para recuperar a ductilidade da liga, embora a resistência mecânica também reduza um pouco após este tratamento $[5,8]$.

Com a realização de um tratamento térmico de recozimento em um material deformado, tem-se a redução das tensões residuais geradas pelo encruamento (recuperação) e/ou posteriormente a nucleação de grãos livres de tensões (recristalização), que acontecem no interior dos grãos deformados, em função da taxa de aquecimento e do tempo/temperatura adotado no encharque. Diante da 
manutenção em uma determinada temperatura, acontece o crescimento destes núcleos recristalizados consumindo os grãos deformados/ recuperados, resultam em uma nova estrutura de grãos, com uma baixa densidade de discordâncias [2, 9, 10]. Após a completa recristalização, se o material for mantido por mais tempo de manutenção na temperatura adotada ou se a temperatura for incrementada, caso não haja barreiras (solução sólida ou precipitados) para a movimentação dos contornos de grãos dos grãos recristalizados, ter-se-á o fenômeno de crescimento de grão, que também é um fenômeno assistido pela difusão como os anteriores.

Para a ocorrência da nucleação da recristalização ou para que a cinética da recristalização seja aumentada, além dos fatores estruturais do material, é necessário o incremento da temperatura e/ou tempo de permanência para que a mesma aconteça [10].

Este trabalho tem como objetivo, estudar a evolução microestrutural de uma liga de alumínio 7475-T7351 laminada convencionalmente a temperatura ambiente, e posteriormente submetida ao tratamento térmico de recozimento para recristalização a $500^{\circ} \mathrm{C}$ durante 15 minutos e a $350^{\circ} \mathrm{C}$ durante 1500 minutos. Tal objetivo se fundamenta na compreensão do efeito destes na recristalização em condições de temperatura de encharque para solubilizar a liga $\left(500^{\circ} \mathrm{C}\right)$ com tempo relativamente curto (15 minutos) versus uma temperatura mais baixa $\left(350^{\circ} \mathrm{C}\right) \mathrm{com}$ tempo significativamente mais longo (1500 minutos) de forma a evitar a solubilização dos precipitados pré-existentes. Para tal objetivo, foram usadas as técnicas de Microscopia Óptica (MO), para avaliar evolução sob as condições de tratamento, e a Microscopia Eletrônica de Transmissão (MET), para caracterizar os precipitados préexistentes na condição como recebida.

\section{MATERIAL E MÉTODOS}

Foi utilizado como material de estudo uma liga de alumínio 7475-T7351 (segundo a norma SAE AMS4202), na forma de chapa laminada a quente com uma espessura inicial de $12,5 \mathrm{~mm}$ (denominada neste estudo como amostra CR).

Para a etapa de laminação convencional (fabricante FENN MFG. Co. - modelo D51710:1973 - cilindros com diâmetros de 133,70 mm) utilizou-se corpos de prova provenientes da condição CR com dimensões de aproximadamente $40 \times 30 \times 12,5$ $\mathrm{mm}$ (DL $\times$ DT $\times$ DN, respectivamente). Foram realizados 14 passes de laminação a temperatura ambiente para reduzir a espessura da amostra para $3 \mathrm{~mm}$. A laminação teve uma redução aproximada de $10 \%$ em relação a espessura antes de cada passe. Foi retirada uma amostra desta condição e denominada de amostra LC. Outros dois pedaços foram submetidos a tratamento térmico de recozimento para recristalização, ambos em um forno de resistência elétrica, fabricante EDG - modelo 3000. O primeiro tratamento térmico foi realizado a uma temperatura de $500^{\circ} \mathrm{C}$ durante 15 minutos, originando a amostra LC15, e o segundo tratamento térmico foi realizado com uma temperatura de $350^{\circ} \mathrm{C}$ durante 25 horas (1500 minutos), originando a amostra LC1500.

Para a visualização das amostras via microscopia óptica (MO), as mesmas foram embutidas em resina epoxy, lixadas com lixas de carbeto de silício de 220 a 2500 mesh, polidas mecanicamente com abrasivos de diamantes, com granulometrias de $6 \mu \mathrm{m}, 3 \mu \mathrm{m}$ e $1 \mu \mathrm{m}$ dispersas em panos distintos de polimento. $\mathrm{O}$ tempo aproximado de polimento em cada pasta de diamante foi de 15 minutos, sendo posteriormente lavadas em água corrente e álcool, e secadas com jato de ar quente. 
Após o polimento mecânico, a fim de remover os riscos restantes da etapa de polimento mecânico, as amostras foram polidas eletroliticamente em solução de $30 \% \mathrm{HNO}_{3}$ e $70 \%$ de Metanol, pré-resfriada a $-30 \% \mathrm{C}$, com uma voltagem de $15 \mathrm{~V}$ durante 10 a 20 segundos. Após o polimento eletrolítico, as amostras foram atacadas com o reagente Keller $(2,5 \% \mathrm{HNO}, 1,5 \%$ de $\mathrm{HCl}, 1,0 \%$ de $\mathrm{HF}$ e $95 \%$ de $\mathrm{H}_{2} \mathrm{O}$ em volume) durante 40 segundos, para que fosse evidenciado os contornos dos grãos.

Para a visualização e registro da microestrutura, foi utilizado um microscópio óptico MO (fabricante Olympus - modelo BX53M), acoplado a uma câmera digital (fabricante Olympus, modelo SC30), controlada pelo software de aquisição de imagens LCmicro. Para as amostras em estudo, foram realizadas visualizações e registro de imagens em regiões associadas a $1 / 4$ e $1 / 2$ da espessura das amostras, com ampliações de 200x (menor aumento) e 500x (maior aumento).

As amostras da condição como recebida analisadas via microscopia eletrônica de transmissão (MET) foram preparadas da seguinte forma: (i) primeiramente foram extraídas chapas finas (com espessuras entre 250 e $350 \mu \mathrm{m}$ ) correspondentes a seção transversal a direção de laminação da amostra CR; (ii) após a extração das chapas, as mesmas foram lixadas com lixas de 1200 mesh até atingirem uma espessura aproximada de $200 \mu \mathrm{m}$; (iii) os discos (com $3 \mathrm{~mm}$ de diâmetro) foram extraídos por meio de uma punção mecânica, cujos discos foram afinados até uma espessura aproximadamente de $100 \mu \mathrm{m}$ utilizando-se lixas de 1200 mesh; (iv) e por último, foi realizado um polimento eletrolítico até obter um furo em uma região próxima ao centro da amostra/disco com auxílio do aparelho TenuPol-5 da Struers. Para este polimento foi utilizado uma solução de $30 \%$ de ácido nítrico $\left(\mathrm{HNO}_{3}-65 \%\right.$ PA) e $70 \%$ de metanol $\left(\mathrm{CH}_{3} \mathrm{OH}\right)$ resfriada a $-30^{\circ} \mathrm{C}$. Utilizou-se uma voltagem de $12 \mathrm{~V}$ e uma vazão de 25 unid. arb.

As análises de microscopia eletrônica de transmissão foram conduzidas em um microscópio do fabricante JEOL. As análises foram realizadas com uma tensão de aceleração de 200 kV.

\section{RESULTADOS E DISCUSSÃO}

$\mathrm{Na}$ Figura 1 são apresentadas as imagens obtidas por microscopia óptica, da amostra CR com menor ampliação $(a, c)$ e maior ampliação $(b, d)$, visualizadas em regiões a $1 / 4(a, b)$ e $1 / 2$ (c, d) da espessura. Na Figura 2 são apresentadas imagens obtidas por microscopia eletrônica de transmissão da amostra CR com menor ampliação (a) e maior ampliação (b), ambas visualizadas em regiões próximas a 1/2 espessura da amostra CR.

Segundo as imagens apresentadas da Figura 1, pode-se observar a presença de precipitados grosseiros, indicados por PG1, cujos precipitados de dimensões aproximadas são também observados nas amostras LC, LC15 e LC1500 (Figuras 2, 3 e 4, respectivamente, que serão apresentadas posteriormente). Estes precipitados são originados do tratamento térmico prévio realizado na amostra $C R$, ou seja, 0 tratamento térmico -T7351, no qual uma das etapas deste tratamento térmico consiste em realizar um superenvelhecimento na amostra, cujo tratamento térmico proporciona precipitados grosseiros e estáveis [5, 6].

Conforme pode-se observar nas imagens da amostra CR obtidas por microscopia eletrônica de transmissão (Figura 2), há precipitados com formato de bastonetes (indicados por "PF)", os quais tem dimensões entre $20-30 n m$, e estão orientados 
em uma mesma direção. Estes precipitados não são observados nas imagens da Figura 1, devido ao limite de resolução do microscópio óptico.
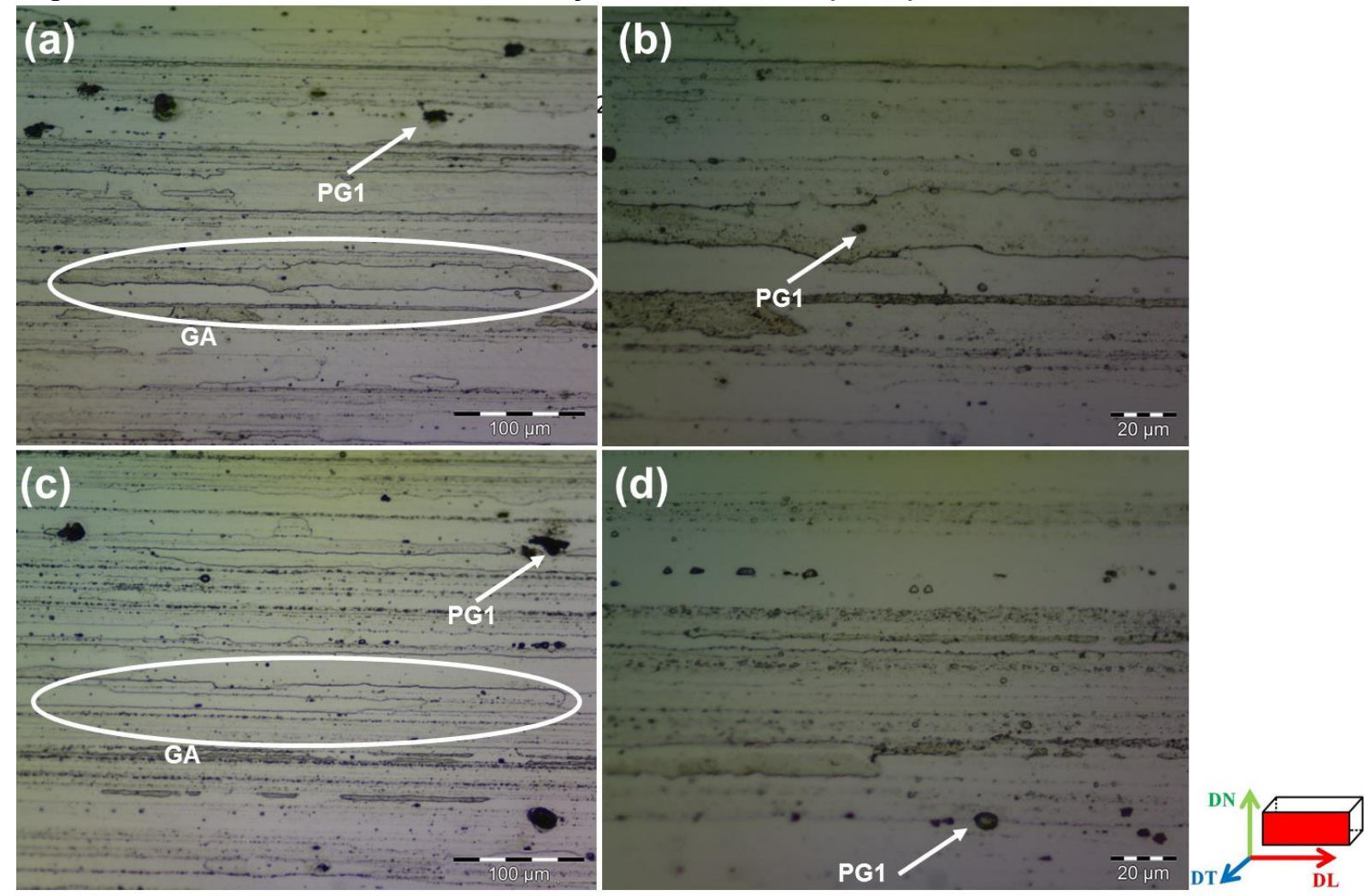

Figura 1. Microestrutura da amostra $C R$ com menor ampliação $(a, c)$ e maior ampliação (b, d), visualizadas em regiões a $1 / 4(a, b)$ e $1 / 2$ (c, d) da espessura. Direção de laminação (DL), MO. Na Figura, "PG1" indicam os precipitados grosseiros preexistentes na matriz e "GA" grãos alongados.
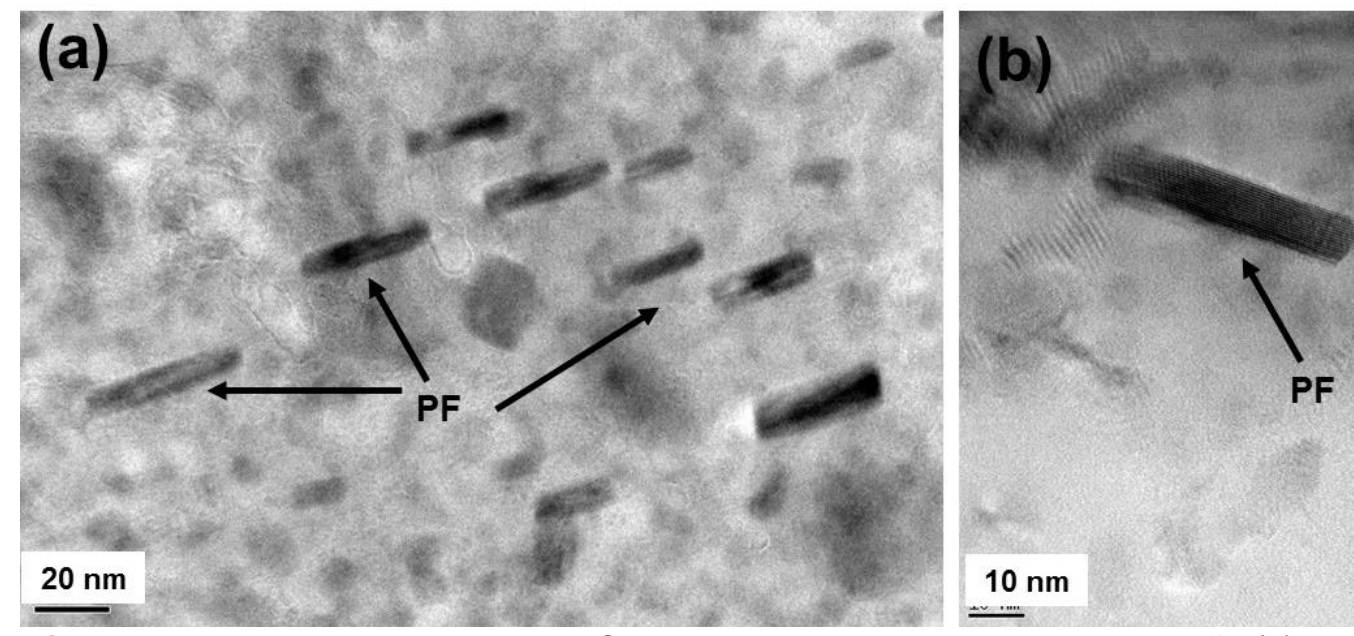

Figura 2. Microestrutura da amostra CR obtida por MET com menor ampliação (a) e maior ampliação (b), visualizadas em regiões próximas a $1 / 2$ espessura. Na Figura, "PF" indicam os precipitados finos preexistentes na matriz.

Nas Figuras 3 a 5 são apresentadas as imagens obtidas por microscopia óptica, das amostras LC, LC15 e LC1500, respectivamente, com menor ampliação (a e c) e

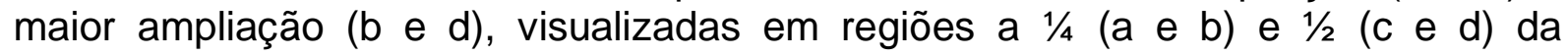
espessura. 

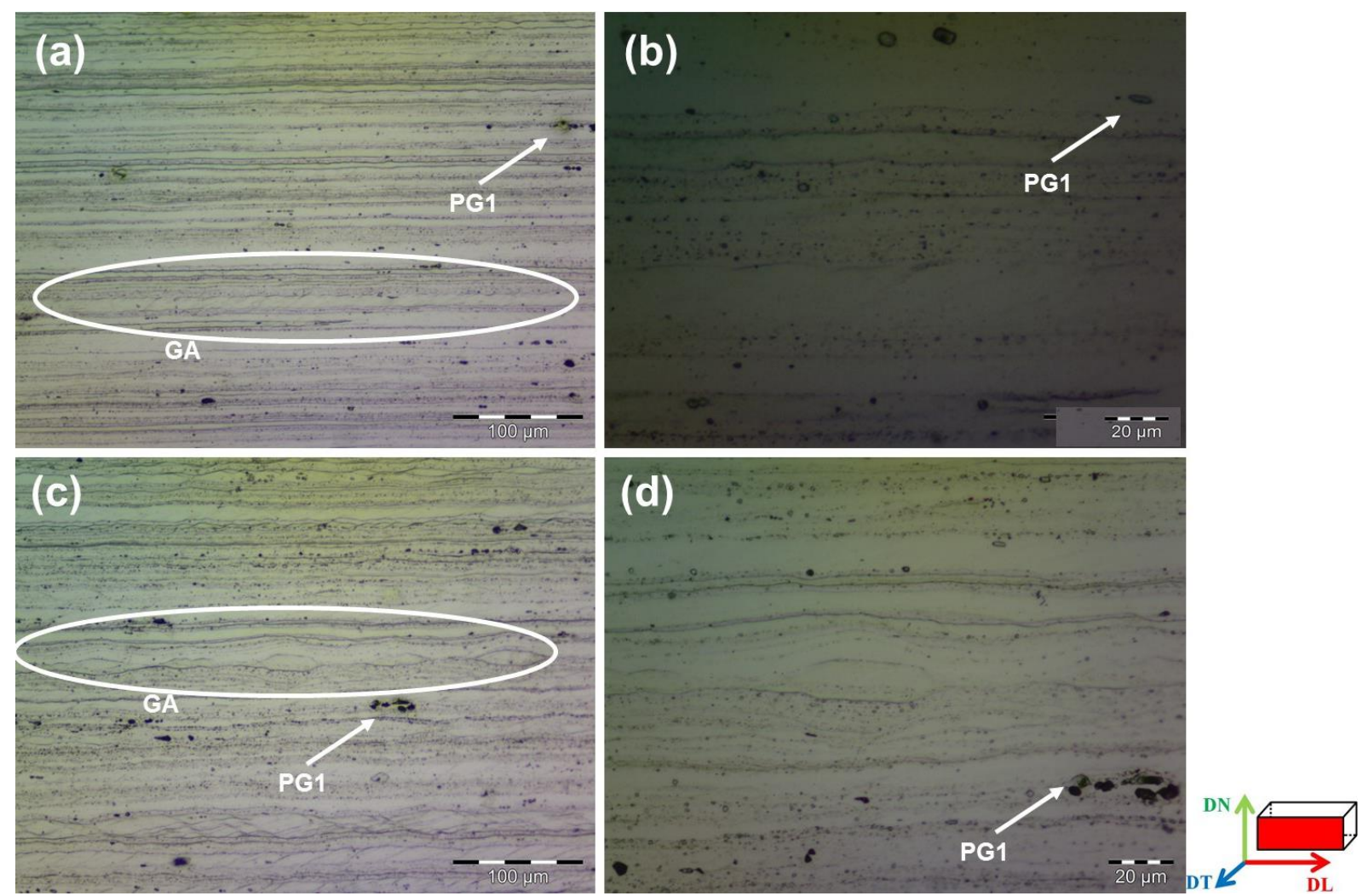

Figura 3. Microestrutura da amostra LC com menor ampliação $(a, c)$ e maior ampliação $(b, d)$, visualizadas em regiões a 1/4 (a, b) e 1/2 (c, d) da espessura. Direção de laminação (DL), MO. Na Figura, "PG1" indicam os precipitados grosseiros preexistentes na matriz e "GA" grãos alongados.
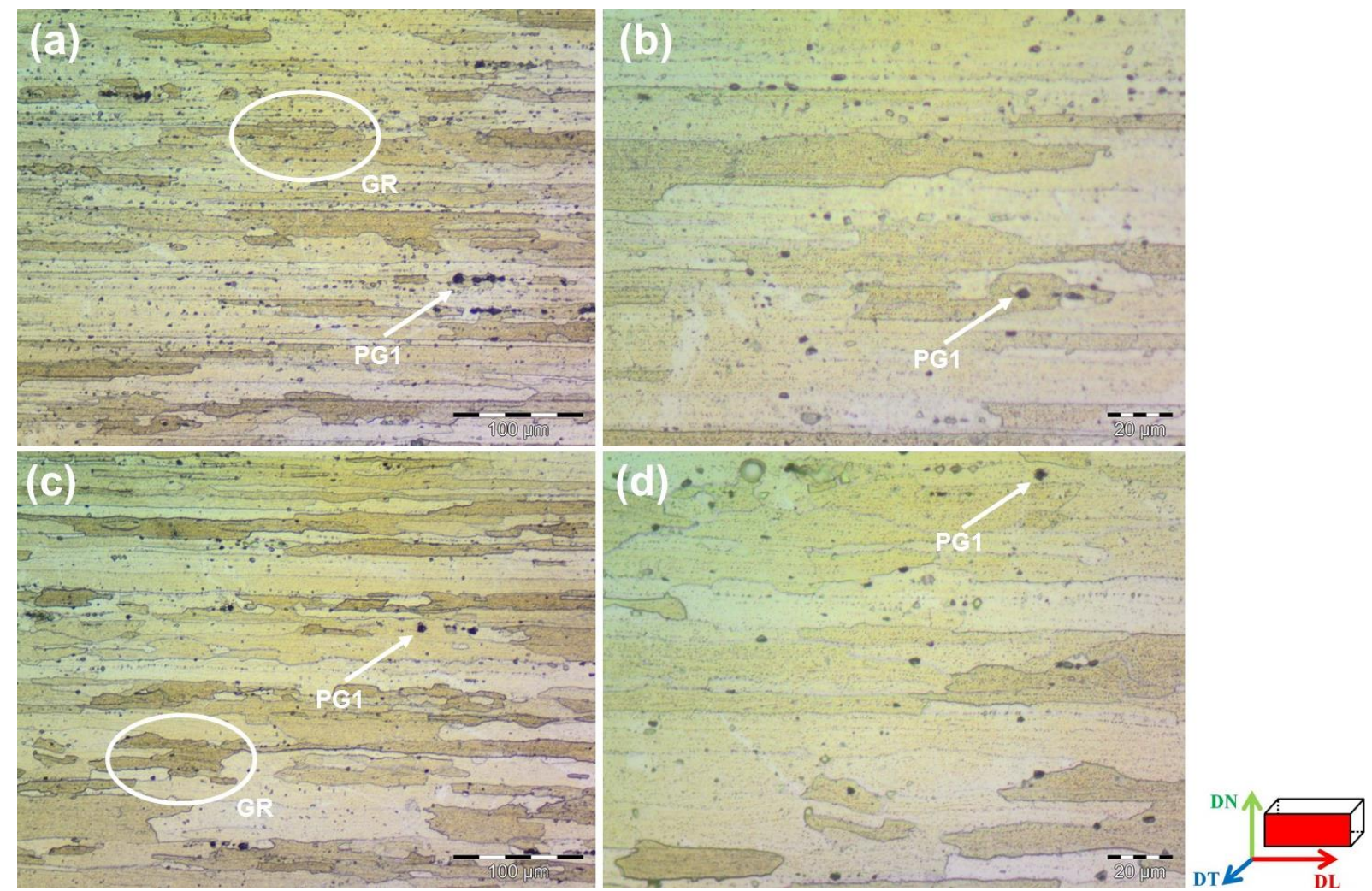

Figura 4. Microestrutura da amostra LC15 com menor ampliação (a, c) e maior ampliação (b, d), visualizadas em regiões a $1 / 4(a, b)$ e $1 / 2$ (c, d) da espessura. Direção de laminação (DL), MO. Na Figura, "PG1" indicam os precipitados grosseiros preexistentes na matriz e "GR" grãos recristalizados. 

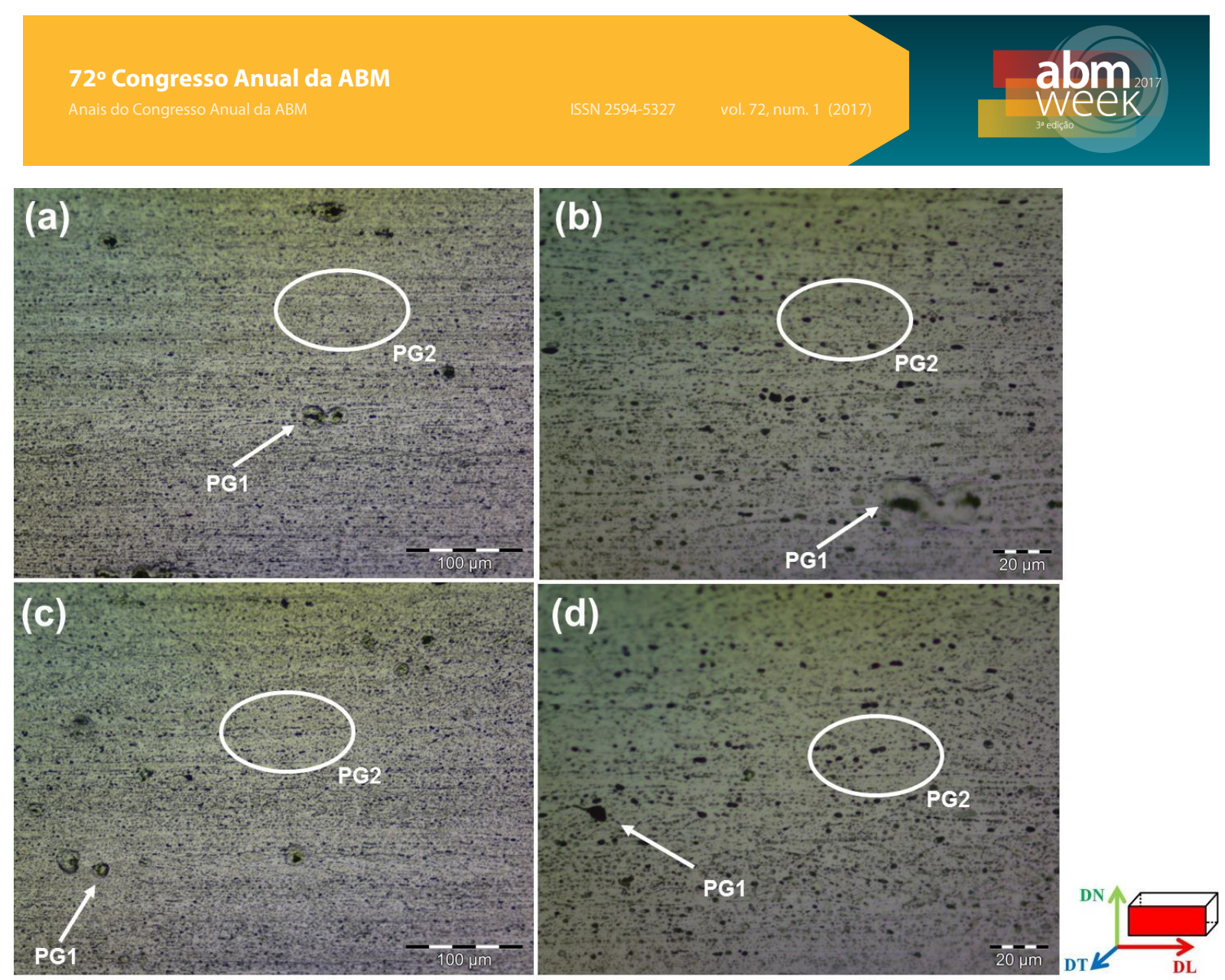

Figura 5. Microestrutura da amostra LC1500 com menor ampliação (a, c) e maior ampliação (b, d), visualizadas em regiões a $1 / 4(a, b)$ e $1 / 2$ (c, d) da espessura. Direção de laminação (DL), MO. $\mathrm{Na}$

Figura, "PG1" indicam os precipitados grosseiros preexistentes na matriz e "PG2" precipitados grosseiros que surgiram após o tratamento térmico de recozimento com 1500 minutos de encharque.

Comparando as amostras LC, LC15 e LC1500 (Figuras 3, 4 e 5, respectivamente) com a amostra CR (Figura 1), observa-se que a laminação convencional e os tratamentos térmicos realizados (recozimento a $500^{\circ} \mathrm{C} / 15$ minutos e $350^{\circ} \mathrm{C} / 1500$ minutos), aparentemente não influenciaram os precipitados indicados por "PG1", no que diz respeito a sua fração volumétrica e/ou tamanho dos mesmos, pois aparentemente continuam com o mesmo formato, fração volumétrica e tamanho. Para se ter uma maior certeza deste comportamento, serão realizadas em trabalhos futuros outras análises mais detalhadas, como por exemplo, visualização pelo detector de elétrons retroespalhados/MEV, e estimativa da fração volumétrica dos precipitados grosseiros por técnicas de metalografia quantitativa.

Comparando as imagens obtidas das amostras em estudo, em posições referentes a $1 / 4$ e $1 / 2$ espessura, não foi evidenciado diferenças significativas na microestrutura das amostras, no que diz respeito a fração volumétrica dos precipitados apresentados, ou aspecto dos grãos.

Em relação a morfologia dos grãos, observa-se possíveis grãos grosseiros e uma tendência de grãos alongados na direção de laminação (DL) nas amostras $C R$ (Figura 1) e amostra LC (Figura 3), indicados por "GA" nas imagens. A amostra LC15, apresenta grãos alongados, porém o aspecto do mesmo já é bem diferente do aspecto dos grãos das amostras CR e LC, ou seja, o tratamento térmico de recozimento para recristalização com os parâmetros usados $\left(500^{\circ} \mathrm{C} / 15\right.$ minutos) foi efetivo para promover a recristalização da amostra LC (grãos indicados por "GR"). Para melhor caracterizar o aspecto dos grãos, ou seja, se estão ou não alongados na direção de laminação tendo em vista mapeamento de contornos de grão, serão 
conduzidos como trabalhos futuros a realização de mapeamento microestrutural via detector de Difração de Elétrons Retroespalhados - EBSD / MEV.

No que diz respeito aos parâmetros usados nos tratamentos térmicos de recozimento para recristalização, ao se comparar as amostras LC15 (Figura 4) com a amostra LC1500 (Figura 5), pode-se observar uma grande diferença microestrutural entre as amostras, ou seja, na amostra LC15, observa-se grãos recristalizados alongados na direção de laminação, e com uma aparente maior fração volumétrica de precipitados do tipo "PG2" em posições a 1/4 da espessura em comparação com o campo visualizado a $1 \frac{1}{2}$ da espessura. Já para a amostra LC1500 observa-se uma microestrutura com grande fração volumétrica de precipitados grosseiros ("GR2") que apareceram após o tratamento térmico de recozimento com longo tempo de encharque. Os precipitados do tipo "PG2", podem ter sua origem da coalescência dos precipitados do tipo "PF" devido ao longo tempo de tratamento térmico da amostra LC1500.

Outro fato observado, foi que para as outras condições em estudo, um ataque químico com a solução de Keller durante $40 \mathrm{~s}$ segundos foi o suficiente para revelar os contornos dos grãos [12], porém para a amostra LC1500 testes de imersão até 300 s não foram efetivos para revelar os contornos de grão. Isto indica uma possível modificação de composição química da matriz, fato este observado pela não reatividade da matriz com $o$ reagente usado nas outras amostras, e consequentemente, modificação da composição química dos precipitados previamente existentes na matriz, após o tratamento térmico de recozimento para recristalização com tempo de encharque de 1500 minutos.

Para melhor caracterizar o aspecto, composição química e dispersão dos precipitados, ou seja, se são ou não de composição química distinta dos precipitados presentes na amostra LC15, serão conduzidos como trabalhos futuros a realização de composição química destes precipitados via Espectroscopia de Energia Dispersiva de Raios-X EDS / MEV e/ou MET.

Para verificar se houve recristalização na amostra LC1500, será testado em trabalhos futuros outras soluções de ataque químico que revelem os contornos dos grãos, e desta forma, será possível verificar se a amostra LC sofreu recristalização com temperaturas de encharque de $350^{\circ} \mathrm{C}$ e tempos longos de tratamentos térmicos, como por exemplo, 25 horas (1500 minutos). Outro fato que também será averiguado em trabalhos futuros, é o comportamento da dureza desta liga nas condições em estudo, pois com tempos longos de tratamentos térmicos, ocorreu possivelmente o coalescimento de precipitados finos preexistentes da matriz, e desta forma é esperado que a dureza da amostra LC1500 seja menor do que a dureza da amostra LC15. Como também, pretende-se avaliar algumas das propriedades mecânicas que podem ser extraídas de ensaios de ultramicrodureza instrumentada para análises das condições em estudo.

\section{CONCLUSÃO}

De acordo com os resultados apresentados, pode-se concluir que:

- A amostra CR apresenta precipitados com dimensões entre 20 - 30nm, cujos precipitados possuem o mesmo alinhamento;

- A laminação convencional e os tratamentos térmicos de recozimento para recristalização, não modificaram aparentemente o formato e a fração volumétrica dos precipitados do tipo "PG1"; 
- Um tratamento térmico de recozimento para recristalização conduzido a uma temperatura de $500^{\circ} \mathrm{C}$ durante 15 minutos, foi o suficiente para provocar a recristalização da amostra LC, porém são necessárias novas análises para verificar se o tratamento térmico com uma temperatura de $350^{\circ} \mathrm{C}$ durante 1500 minutos foi 0 suficiente para recristalizar a amostra LC.

- Aparentemente houve o coalescimento de precipitados com longos tempos de tratamento térmico (amostra LC1500).

\section{Agradecimentos}

Os autores agradecem a CAPES pelo auxílio financeiro via bolsa de estudos de mestrando (Diniz SB, da Cruz RB) e de doutorando (Diniz SB, da Cruz RB), e ao CBPF pelos recursos para preparação de amostras e caracterização microestrutural via microscopia eletrônica de transmissão.

\section{REFERÊNCIAS}

1 ASM Handook. Properties and Selection: Nonferrous alloys and specialpurpose materials. Almere: ASM International; 1990.

2 Lima EPR. Estudo da cinética de recristalização da liga de alumínio AA 8011 na condição H18 [dissertação de mestrado]. Recife: Universidade Federal de Pernambuco; 2002.

3 ABAL. Fundamentos e aplicações do alumínio, associação brasileira do alumínio (ABAL), São Paulo, 2004.

4 Minatel R. Um Estudo comparativo sobre a recristalização de chapas de alumínio AA1200 e AA3003 obtidas por lingotamento contínuo (twin rollcaster) e por fundição de placas (direct chill) [dissertação de mestrado]. São Paulo: Universidade de São Paulo; 2009.

$5 \quad$ ASM Handook. Heat treating. Almere: ASM International; 1991.

6 Braga APV. Análise de ligas de alumínio aeronáuticas conformadas por jateamento com granalhas - caracterização e previsão de deformação [dissertação de mestrado]. São Paulo: Universidade de São Paulo; 2011.

7 Oliveira JCPT. Estudo da microestrutura e da textura durante a laminação a frio e a recristalização de alumínio com diferentes níveis de pureza [tese de doutorado]. São Paulo: Universidade de São Paulo; 2009.

8 Bresciani Filho E, Zavaglia CAC, Button ST, Gomes E, Nery FAC. Conformação plástica dos metais. São Paulo: Editora da Unicamp; 1991.

9 Slámová M, Ocenásek V, Voort GV. Polarized light microscopy: utilization in the investigation of the recrystallization of aluminum alloys. Materials Characterization. 2004; 52, 165-177.

10 Humphreys FJ, Hatherly M. Recrystallization and relates annealing phenomena. Oxford: Pergamon; 2004.

11 Padilha AF, Siciliano JR F. Encruamento, recristalização, crescimento de grão e textura. São Paulo: ABM Livros; 2005.

12 Diniz SB, Cruz RB, Paula AS, Brandão LPM. Evolução microestrutural de uma liga de alumínio 7474-T7351 submetida a laminação cruzada e recristalizada com diferentes tempos de encharque. In: Associação Brasileira de Metalurgia, Materiais e Mineração. Submetido a AbmWeek 2017; 2017; São Paulo, Brasil. São Paulo: ABM; 2017. p. 1-11 